\title{
PURIFICATION AND FUNCTIONAL CHARACTERIZATION OF TWO \\ FIBRINOGENOLYTIC ENZYMES FROM Bothrops alternatus VENOM
}

\section{COSTA J. O. (1), PETRI C. B. (1), HAMAGUCHI A. (1), HOMSI-BRANDEBURGO}

M. I. (1), OLIVEIRA C. Z. (2), SOARES A. M. (2), OLIVEIRA F. (3)

(1) Institute of Genetics and Biochemistry, Federal University of Uberlândia, Uberlândia, Minas Gerais State, Brazil; (2) Department of Clinical, Toxicological and Bromatological Analyses, School of Pharmaceutical Sciences, University of São Paulo, USP, Ribeirão Preto, São Paulo State, Brazil; (3) Institute of Biomedical Sciences, Federal University of Uberlândia, Uberlândia, Minas Gerais State, Brazil.

\begin{abstract}
Two fibrinogenolytic enzymes, Bothrops alternatus metalloprotease isoform (BaltMP)-I and II, were purified from Bothrops alternatus venom using Diethylaminoethyl (DEAE) Sephacel, Sephadex G-75 and Heparin-Agarose column chromatography. Purified BaltMP-I and II ran as single protein bands on analytical polyacrylamide gel electrophoresis and showed molecular weights of 29000 and 36000, respectively, under reducing conditions in sodium dodecyl sulfate polyacrylamide gel electrophoresis (SDS-PAGE). BaltMP-II, but not BaltMP-I, displayed blood-clotting activity in bovine plasma, which was about 10-fold higher than that of the crude venom. Both enzymes were proteolytically active against bovine fibrinogen as substrate. When fibrinogen and each enzyme were incubated at $37^{\circ} \mathrm{C}$, at a ratio of $1: 100(\mathrm{w} / \mathrm{w})$, BaltMP-Il cleaved preferentially the A $\alpha$-chain and more slowly the $B \beta$-chain. The action of BaltMP-I was similar, but lower. None of the proteases degraded the $\gamma$-chain of fibrinogen. The fibrinogenolytic activity of the enzymes was inhibited by 1,10-phenanthroline, suggesting they are metalloproteases. Since both enzymes were found to cause defibrinogenation when intraperitoneally (i.p.) administered to mice, they can be of medical interest as a therapeutic agent in the treatment and prevention of arterial thrombosis.
\end{abstract}

KEY WORDS: snake venom, Bothrops alternatus, metalloproteases, functional characterization, fibrinogenolytic activity, defibrinogenation in vivo.

CONFLICTS OF INTEREST: There is no conflict.

\section{CORRESPONDENCE TO:}

FÁBIO OLIVEIRA, Instituto de Ciências Biomédicas, Universidade Federal de Uberlândia, 38400-902, Uberlândia-MG, Brasil. Phone: 55343218 2200. Fax: 5534 3218 2247. Email: foliveira@umuarama.ufu.br. 


\section{INTRODUCTION}

Bothrops snake venoms contain several different proteins affecting the hemostatic mechanism. Some of them display pro and anticoagulant activities $(15,33,38)$. Other components are able to affect platelet function, acting either as pro-aggregating inducers or as platelet inhibitors, whereas others produce vasodilation $(6,11,18,19$, 23, 39). According to their interaction with inhibitors, pro and anticoagulant components in snake venoms are divided into serine and metalloproteases $(1,20$, 34, 37). Direct fibrin(ogen)olytic metalloproteases degrade preferentially the A $\alpha$-chain of fibrinogen followed by the $\beta$-chain. The enzymes degrading the $\beta$-chain without fibrinolysis belong to the serine proteases group (17). Some metalloproteases have fibrinogenolytic or fibrinolytic activities and are named fibrinogenases. These enzymes have been classified as $\alpha, \beta$ and $\gamma$-fibrinogenases $(24,26,28,32)$ based on their specificity for cleaving fibrinogen polypeptide chains. These enzymes have been purified from the venoms of Bothrops moojeni, B. jararacussu, B. jararaca, $B$. neuwiedi, Agkistrodon halys brevicadus, and Trimeresurus elegans. The primary and three-dimensional structures of several metalloproteases have been determined, showing that they are structurally related $(20,25,29)$.

Recently, a 60kDa hemorrhagic metalloprotease, BjussuMP-I, has been isolated from Bothrops jararacussu venom. Because platelets play a crucial role in hemostasis and are targets of metalloproteases disintegrin-like/disintegrins, BjussuMP-I has been investigated as inhibitor of platelet aggregation and its deduced full-length sequence by cDNA cloning has also been reported $(21,22)$.

Proteinases with fibrin(ogen)olytic and anti-clotting properties find potential application in drug development to treat thrombotic disorders which result in fatal heart attack and stroke. The current paper describes the purification and functional characterization of two proteolytic enzymes, called BaltMP-I and II, from the venom of Bothrops alternatus as well as some results of their biochemical characterization including blood-clotting, fibrinogenolytic and defibrinating activities.

\section{MATERIALS AND METHODS}

\section{Materials}

Bothrops alternatus dried venom was obtained from the Reptiles Sector at Federal University of Uberlândia, Brazil. Bovine fibrinogen, aprotinin, phenylmethylsulfonyl 
fluoride (PMSF), ethylenediaminetetraacetate (EDTA), 1,10-phenanthroline and $\beta$ mercaptoethanol were from Sigma (USA). All other chemicals were of analytical grade.

\section{Isolation of BaltMP-I}

Bothrops alternatus venom (200mg) was dissolved in 50mM ammonium bicarbonate buffer, $\mathrm{pH} 7.8$, and clarified by centrifugation at $10000 \mathrm{Xg}$ for $10 \mathrm{~min}$. The supernatant solution was chromatographed on a DEAE-Sephacel column $(1.7 \times 15 \mathrm{~cm})$, previously equilibrated with $50 \mathrm{mM}$ ammonium bicarbonate, $\mathrm{pH} 7.8$, and eluted with convex concentration gradient $(50 \mathrm{mM}-1 \mathrm{M})$ of the same buffer. Fractions of $3 \mathrm{ml} / \mathrm{tube}$ were collected, their absorbances at $\lambda=280 \mathrm{~nm}$ were read and those corresponding to peak D6 were all together lyophilized, dispersed in 50mM ammonium bicarbonate, $\mathrm{pH} 7.8$, and applied to a Sephadex G-75 column $(2 \times 100 \mathrm{~cm})$ previously equilibrated with the same buffer. To isolate BaltMP-I, the fibrinogenolytic fraction (peak D6G2) was lyophilized and applied to a Heparin-Agarose column $(1.7 \times 15 \mathrm{~cm})$ previously equilibrated with $10 \mathrm{mM}$ Tris- $\mathrm{HCl}+5 \mathrm{mM} \mathrm{CaCl}_{2}, \mathrm{pH} 7$, and eluted with $10 \mathrm{mM}$ Tris- $\mathrm{HCl}$ $+1 \mathrm{M} \mathrm{NaCl}, \mathrm{pH}$ 7. The flow rate was $40 \mathrm{ml} / \mathrm{h}$ and $2 \mathrm{ml}$ fractions were collected. The isolated enzyme was named $B$. alternatus metalloprotease I (BaltMP-I).

\section{Isolation of BaltMP-II}

To isolate BaltMP-II, the protein fractions (peak D3) showing fibrinogenolytic and blood-clotting activities were pooled, lyophilized and dissolved in $3 \mathrm{ml}$ of distilled water. This sample was applied to a Sephadex G-75 column (2X100cm), equilibrated and eluted with $50 \mathrm{mM}$ ammonium bicarbonate, $\mathrm{pH} 7.8$. The flow rate was $20 \mathrm{ml} / \mathrm{h}$ and $3 \mathrm{ml}$ fractions were collected. The isolated enzyme was named $B$. alternatus metalloprotease II (BaltMP-II).

\section{Electrophoretic Analysis: Molecular Weight Determination}

The molecular weights of BaltMP-I and II were determined using SDS-PAGE (14\%) according to the method of Laemmli (13). Electrophoresis was carried out at $20 \mathrm{~mA} / \mathrm{gel}$ in Tris-glycine buffer, $\mathrm{pH} 8.3$, containing $0.01 \%$ SDS. The molecularweight standard proteins used were phosphorylase b (97000), bovine serum albumin (66000), ovoalbumin (45000), carbonic anhydrase (30000), soybean trypsin inhibitor 
(20100), and $\alpha$-lactalbumin (14400). The slab gels were stained with Coomassie Blue R-250, 0.2\% (w/v), in acetic acid : methanol : water (1 : $5: 5, \mathrm{v} / \mathrm{v})$.

\section{Estimation of Protein Concentration}

Protein concentration was determined according to a micro-biuret method (10), using bovine serum albumin as standard.

\section{Fibrinogenolytic Activity}

Fibrinogenolytic activity was assayed as previously described (25). Fibrinogen $(5 \mu \mathrm{g})$ and enzymes were mixed 1:100 (w/w) and the mixture was incubated at $37^{\circ} \mathrm{C}$ for different time intervals (0-90 $\mathrm{min})$. The reaction was stopped by the addition of an equal volume of a denaturing buffer containing $2 \%(\mathrm{w} / \mathrm{v})$ SDS and $10 \%(\mathrm{v} / \mathrm{v}) \beta$ mercaptoethanol. The reaction products were analyzed using SDS-PAGE and 14\% gels.

\section{Defibrinating Activity}

Defibrinating activity was tested using the method of Gene et al. (7), with slight modifications. Briefly, four Swiss mice (18-20g) were i.p. injected with $5 \mu \mathrm{g}$ of the enzymes and dissolved in $200 \mu$ l saline; control animals received $200 \mu$ l saline. After one hour, animals were anesthetized with ether and bled by cardiac puncture. Whole blood was placed in tubes and kept at $25-30^{\circ} \mathrm{C}$ until clotting occurred.

\section{Blood-Clotting Activity}

Blood samples were collected into $3.8 \%$ sodium citrate $(9: 1, v / v)$ and centrifuged at $2500 \mathrm{Xg}$ for $15 \mathrm{~min}$ at $4^{\circ} \mathrm{C}$ to obtain platelet-poor plasma. Clotting activity was determined by mixing $5 \mu \mathrm{g}$ of enzymes with $200 \mu \mathrm{l}$ of citrated bovine plasma at $37^{\circ} \mathrm{C}$ and by determining the clotting time.

\section{Enzyme Inhibitors}

Inhibition of fibrinogenolytic activity was determined by incubating enzymes $(5 \mu \mathrm{g})$ in $200 \mu \mathrm{l}$ of $50 \mathrm{mM}$ Tris- $\mathrm{HCl}, \mathrm{pH} 7.8$, for $15 \mathrm{~min}$ at room temperature $\left(25^{\circ} \mathrm{C}\right)$ with one of the following inhibitors: $10 \mathrm{mM}$ EDTA, 10mM PMSF, 10mM aprotinin, 10mM 1,10- 
phenanthroline, and 10mM $\beta$-mercaptoethanol. Proteolytic activity was determined as previously described.

\section{RESULTS}

\section{Isolation of BaltMP-I and II}

Bothrops alternatus venom, initially fractionated on DEAE-Sephacel column, displayed six peaks, D1-D6. A typical elution profile of this chromatography is shown in Figure 1A. Fraction D6 was further purified on a Sephadex G-75 column (Figure 1B). Fraction D6G2 from this fractionation was applied to a Heparin-Agarose column (Figure 1C). The non-adsorbed fraction (BaltMP-I) displayed fibrinogenolytic and defibrinating activities. This fraction was free of blood-clotting and hemorrhagic activities. Isolation of the fibrinogenolytic, defibrinating and blood-clotting enzyme (BaltMP-II) was achieved by applying fraction D3 from the DEAE-Sephacel on a Sephadex G-75 (pH 7.8) column (Figure 1D).

The apparent molecular weights of BaltMP-I and II, under reducing conditions, were estimated from the results of SDS-PAGE (Figure 2), being 29000 and 36000, respectively.

\section{Fibrinogenolytic Activity of BaltMP-I and II}

Figures $3 A$ and $3 B$ show the results of SDS-PAGE analyses of incubated mixtures of bovine fibrinogen with each of the isolated enzymes. As shown in the control lane (Figures $3 A$ and $3 B$; Lane 1), reduced bovine fibrinogen was separated into $A \alpha, B \beta$ and $\gamma$-chains. When incubated with BaltMP-I (Figure 3A), the A $\alpha$-chain started to disappear after 15 min of incubation and essentially disappeared within $45 \mathrm{~min}$. B $\beta$ chain started to disappear at the same time but at a speed lower than that of $A-$ chain, and completely disappeared within $90 \mathrm{~min}$. When incubated with BaltMP-II (Figure 3B), A $\alpha$ and B $\beta$-chains completely disappeared within $15 \mathrm{~min}$. Both enzymes appeared to have little or no effect on the $\gamma$-chain after 90 min of hydrolysis.

Figures $3 C$ and $3 D$ show the effects of various inhibitors of the fibrinogenolytic activity of BaltMP-I and II. The fibrinogenolytic activity of both enzymes depends on the presence of a metal ion, since pre-incubation with 1,10-phenanthroline almost completely abolished it. On the other hand, inhibitors of cysteine and serine proteases, namely $\beta$-mercaptoethanol, PMSF and aprotinin, had little or no effect on 
the fibrinogenolytic activity of BaltMP-I and II. EDTA was able to abolish the activity of BaltMP-II but had no effect on that of BaltMP-I.

\section{Blood-Clotting and Defibrinating Activities of BaltMP-I and II}

BaltMP-II, but not BaltMP-I, displayed a blood-clotting activity on bovine plasma, which was about 10-fold higher than that of the crude venom.

In addition, BaltMP-I and II caused defibrinogenation when i.p. administered to mice, making the plasma uncoagulable. Fibrinogen levels became very low one hour after injection of $5 \mu \mathrm{g}$ of each enzyme. Normal fibrinogen levels were only reestablished after 24 hours.

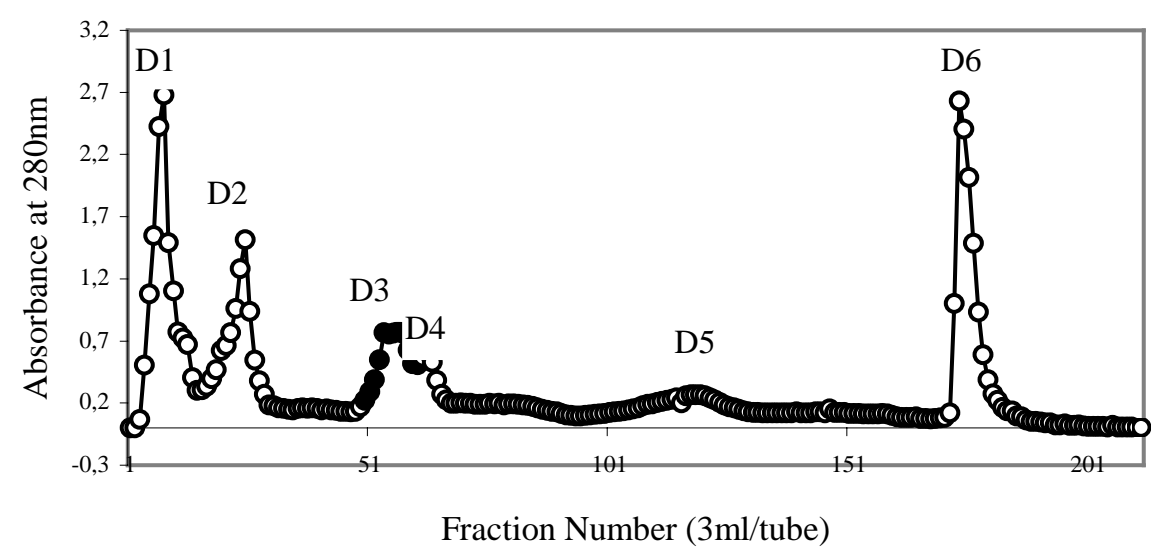

A

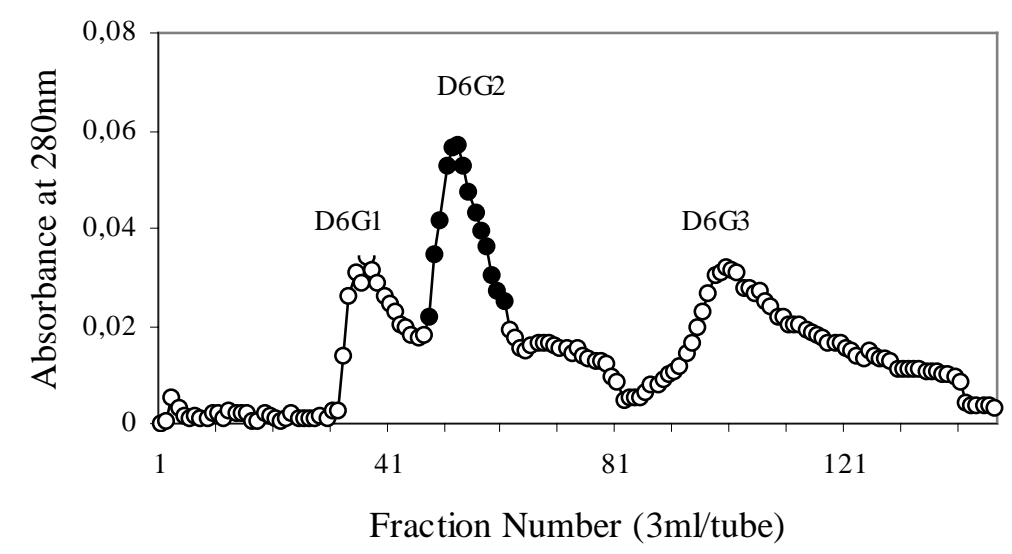

B 


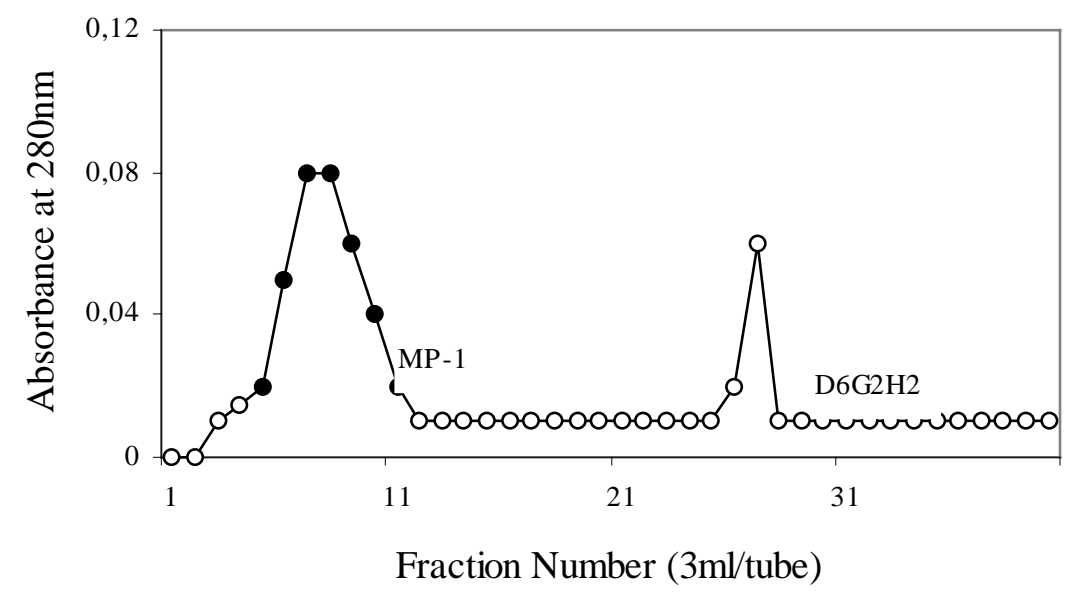

\section{C}

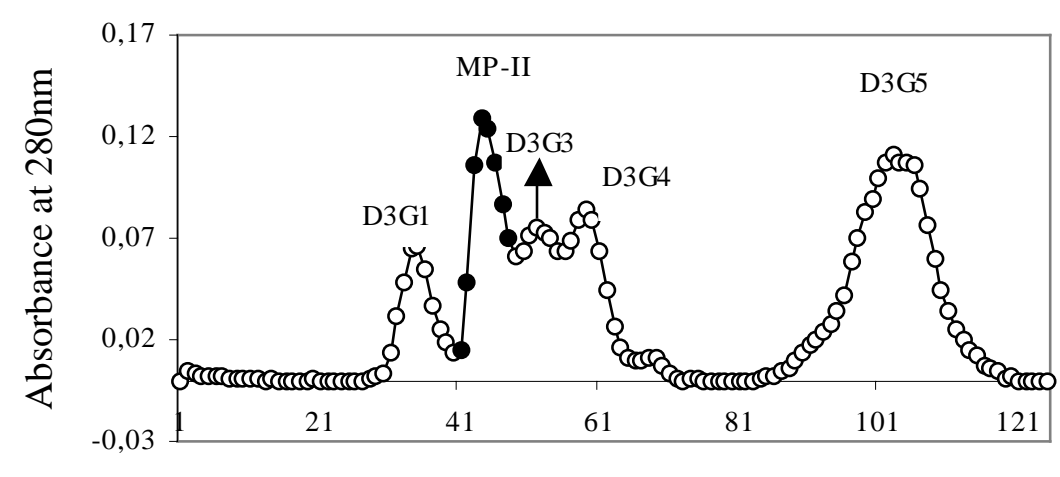

Fraction Number (3ml/tube)

D

Figure 1. Purification of BaltMP-I and II from Bothrops alternatus venom. (A): Fractionation on DEAE-Sephacel: crude venom (200mg) was applied to the column $(1.7 \times 15 \mathrm{~cm})$ and elution was carried out at a flow rate of $20 \mathrm{ml} / \mathrm{h}$ with convex ammonium bicarbonate gradient from $50 \mathrm{mM}$ to $1 \mathrm{M}, \mathrm{pH}$ 7.8. (B): Fractionation on Sephadex G-75: the active fraction (D6) was applied to the column $(2 \times 100 \mathrm{~cm})$ and elution with $50 \mathrm{mM}$ ammonium bicarbonate buffer at $\mathrm{pH} 7.8$ was achieved at a flow rate of $20 \mathrm{ml} / \mathrm{h}$. (C): Fractionation on Heparin-Agarose: the enzyme concentrate (D6G2) was applied to the column $(1.7 \times 15 \mathrm{~cm})$ and elution was carried out at a flow rate of $40 \mathrm{ml} / \mathrm{h}$ with $10 \mathrm{mM}$ Tris- $\mathrm{HCl}$ buffer containing $1 \mathrm{M} \mathrm{NaCl}$ at $\mathrm{pH} 7.0$. The isolated enzyme was named BaltMP-I. (D): Fractionation on Sephadex G-75: the active fraction (D3) was applied to the column $(2 \times 100 \mathrm{~cm})$ and elution with $50 \mathrm{mM}$ ammonium bicarbonate buffer at $\mathrm{pH} 7.8$ was achieved at a flow rate of $20 \mathrm{ml} / \mathrm{h}$. The isolated enzyme was named BaltMP-II. Protein was monitored by absorbance at $280 \mathrm{~nm}$. Fractions pooled are indicated by the closed circles. 


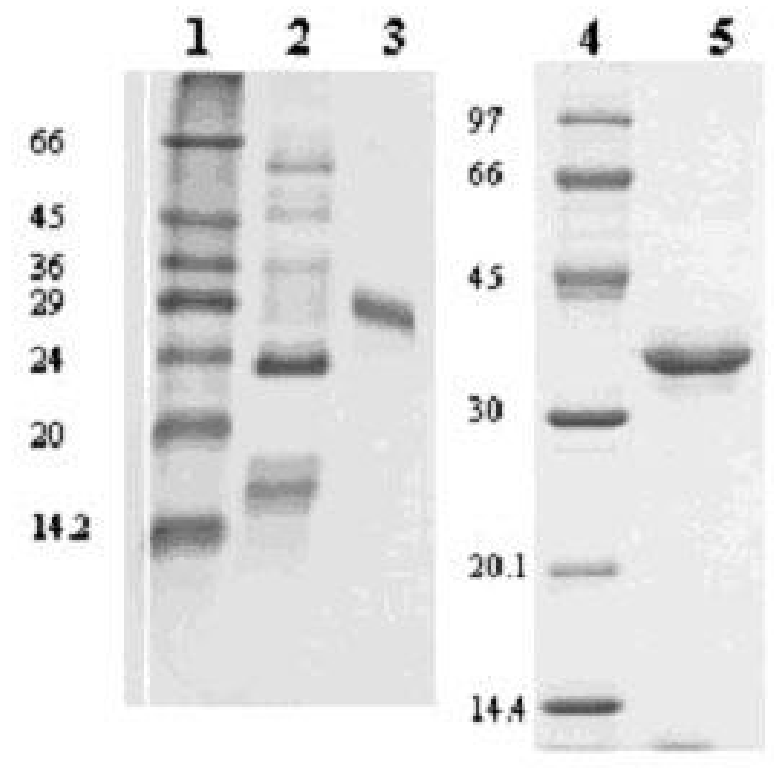

Figure 2. SDS-PAGE analysis of the purified enzymes. The purified enzymes were subjected to electrophoresis in a $14 \%$ sodium dodecylsulfate polyacrylamide gel under reducing conditions. Lanes 1 and 4: Molecular weight markers; Lane 2: Bothrops alternatus venom; Lane 3: reduced BaltMP-I; Lane 5: reduced BaltMP-II. Electrophoresis was carried out at $20 \mathrm{~mA} / \mathrm{gel}$ in Tris-glycine buffer, $\mathrm{pH} 8.3$, containing $0.01 \%$ SDS. The slab gel was stained with Coomassie Blue R-250 and destained with methanol : acetic acid : water $(1: 5: 5, \mathrm{v} / \mathrm{v})$. 


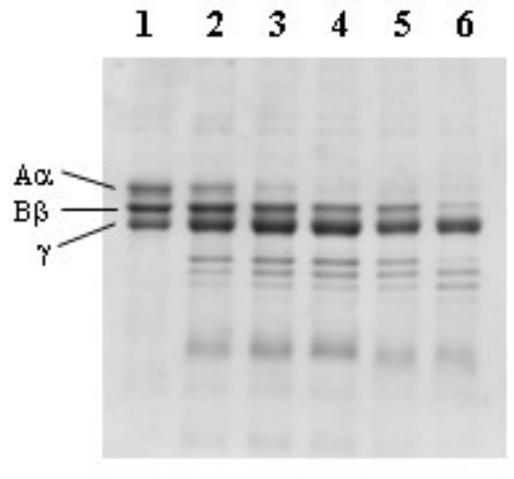

A

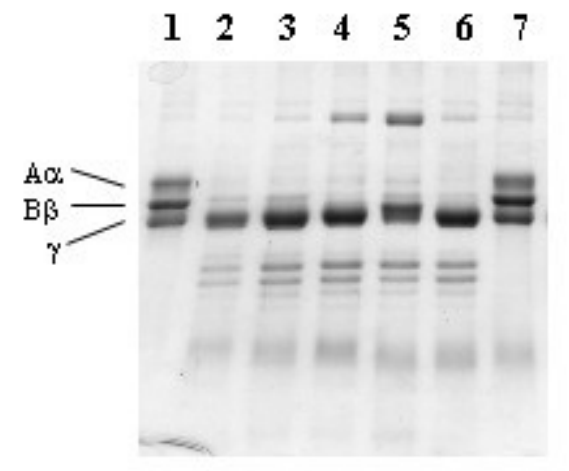

$\mathrm{C}$

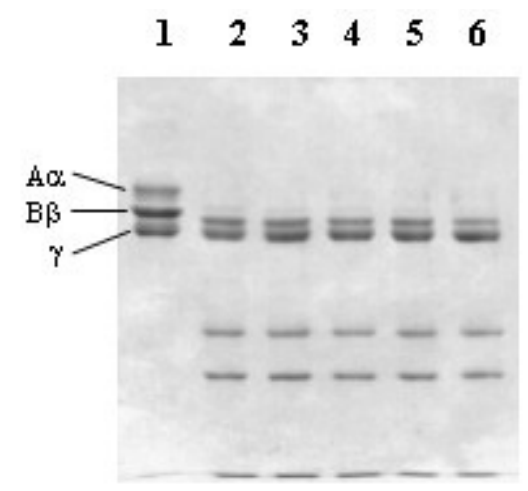

B

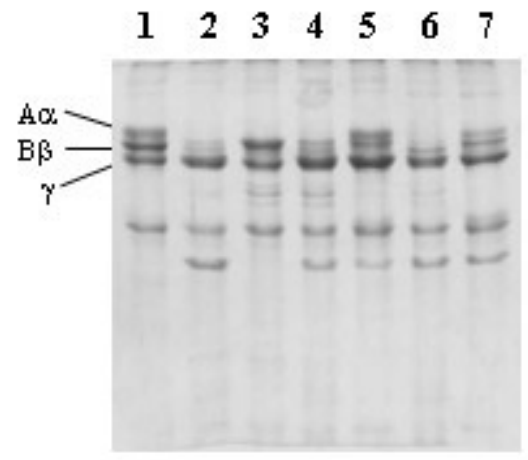

D

Figure 3. Proteolysis of fibrinogen by BaltMP-I and II. (A) and (B): Lane 1: control fibrinogen incubated without enzyme for $60 \mathrm{~min}$; Lanes 2, 3, 4, 5, and 6 : fibrinogen incubated with BaltMP-I and II for 15, 30, 45, 60 and 90 min, respectively. (C) and (D): Lane 1: control fibrinogen incubated without enzyme for $60 \mathrm{~min}$; Lane 2: control fibrinogen incubated with enzyme for $60 \mathrm{~min}$; Lanes 3, 4, 5, 6 and 7: fibrinogen after incubation with BaltMP-I or II + PMSF, aprotinin, EDTA, $\beta$-mercaptoethanol and 1,10-phenanthroline, respectively.

\section{DISCUSSION}

The main feature of $B$. alternatus venom is its high proteolytic activity, responsible for most of the local and systemic effects observed during envenomation by this snake. In the present work, BaltMP-I and II, two proteases active on fibrinogen, were isolated using chromatography on DEAE-Sephacel, Sephadex G-75 and HeparinAgarose. Both enzymes were devoid of hemorrhagic and phospholipase- $A_{2}$ activities but displayed fibrinogenolytic and defibrinogenation activities. Only BaltMP-II exhibited blood-clotting activity.

The final preparations of BaltMP-I and II were analyzed using SDS-PAGE under reducing conditions. In both cases, the isolated enzymes appeared as single protein bands with molecular weights of 29000 and 36000, respectively (the calibration 
curve for estimation of molecular weights is not shown). Such observations indicate that the isolated enzymes are composed of single polypeptide chains.

Based on their domain structure, snake venom metalloproteases (SVMPs) have been classified into four classes, P-I to P-IV $(9,20)$. Metalloproteases of P-I class consist only of the protease domain, those of class P-II consist of protease domain and disintegrin-like domain, and those of class P-III have a third, cysteine-rich domain. Class P-IV SVMPs possess, in addition to class P-III domains, disulfideattached lectin-like domains. Sub-class P-IA proteins display high hemorrhagic activity, whereas those of class P-IB display little or no activity and include neuwiedase from Bothrops neuwiedi venom (29), MOO3 from Bothrops moojeni venom (8) and adamalysin II from Crotalus adamanteus venom (27). The present results suggest that BaltMP-I and II belong to class PI-B. The PI-B SVMPs can also display fibrinogenolytic activity with specificity for the A $\alpha$-chain and they lack arginine-esterase activity.

The fibrinogenolytic activity of both enzymes was analyzed using SDS-PAGE, which demonstrated that they were able to degrade fibrinogen chains, BaltMP-II being most active. BaltMP-I and II showed fibrinogenolytic activity, degrading predominantly the A $\alpha$-chain of fibrinogen and, at longer incubation times, the $B \beta$-chain as well. Furthermore, the fibrinogenolytic products of BaltMP-I revealed a different cleavage pattern compared with BaltMP-II.

Based on the preferential attack on $A \alpha$ or $B \beta$-chain of fibrinogen, venom fibrinogenases can be either $\alpha$ or $\beta$-type. The $\alpha$-fibrinogenases preferentially attack the A $\alpha$-chain and are metalloproteases. They also cleave the B $\beta$-chain, but at a slower rate, whereas $\beta$-fibrinogenases are serine proteases and show arginineesterase activity $(12,36)$. In the current study, results suggested that BaltMP-I and II are $\alpha$-fibrinogenases.

BaltMP-I and II did not digest the $\gamma$-chain, which is common to many venom proteases. This digestion pattern is similar to that of many fibrinogenases isolated from snake venoms, such as that purified from B. moojeni (8) and B. neuwiedi pauloensis (29).

Figure 3 shows the effect of inhibitors of the fibrinogenolytic activity of BaltMP-I and II. Aprotinin is well known for inactivating trypsin, kallikrein, chymotrypsin, and plasmin (3); however, it showed no effect on the fibrinogenolytic activity of BaltMP-I 
and II. Phenylmethylsulfonyl fluoride (PMSF) appeared to have little or no effect on the fibrinogenolytic activity of BatMP-I and II, indicating that both enzymes are not serine proteases. Their fibrinogenolytic activity was inhibited by chelating compounds such as 1,10-phenanthroline, but BaltMP-I was more strongly inhibited than BaltMP-II.

1,10-phenanthroline is highly specific for $\mathrm{Zn}^{2+} . \mathrm{Ca}^{2+}$ forms weak complex with 1,10phenanthroline. Although the $\mathrm{Zn}^{2+}$-specific reactivity of 1,10-phenanthroline inactivates BaltMP-I, it is surprising to note the ineffectiveness of EDTA which, like 1,10-phenanthroline, shows preference and more affinity for $\mathrm{Zn}^{2+}$ than for $\mathrm{Ca}^{2+}$. These results indicated that both BatMP-I and II belong to the metalloproteases family, but have different inhibitor susceptibilities.

Several proteases from snake venoms have potential clinical usefulness for the treatment of human diseases, used as defibrinogenating agents, and are largely used in laboratories for the detection of fibrinogen in samples of heparinized blood (30). These enzymes have been purified from several different snake species (16, 30).

BaltMP-I and II have been shown to induce defibrinogenation. Both enzymes act as benign defibrinogenating agents to remove fibrinogen from the blood. Within minutes of administration of both enzymes there was a depression in the fibrinogen concentration in plasma and within one hour the fibrinogen levels became very low and thus remained for more than 24 hours. These results suggest that the anticoagulant effect of BaltMP-I and II could be attributed to its proteolytic action on fibrinogen, forming fibrin monomers (non cross-linked fibrin), which could be rapidly removed from the circulation (14).

Some fibrin(ogen)olytic enzymes cause rapid defibrinogenation when they are intravenously administered, reducing the whole blood viscosity $(2,4,31)$ and increasing blood flow (5).

Some of these proteases from snake venoms have been used as defibrinogenating agents for a number of clinical conditions including deep vein thrombosis, myocardial infarction, pulmonary embolus, peripheral vascular disease, angina pectoris, surgical adhesives and renal transplant rejection $(30,31,35)$. For this reason, these enzymes have been considered of great interest to medical clinic, mainly those with high degree of purity and devoid of other pharmacological effects. 
In conclusion, two metalloproteases, BaltMP-I and II, were purified from the venom of Bothrops alternatus. Both showed to possess $\alpha$-fibrinogenase activity and strong in vivo anticoagulant properties. Further structure-function studies on theses enzymes are interesting and would probably help develop therapeutic agents related to thrombotic disorders.

\section{ACKNOWLEDGEMENTS}

We thank Professor Vera Lúcia de Campos Brites, Sector of Reptiles, Federal University of Uberlândia, Brazil, for providing Bothrops alternatus venoms. The authors are grateful for the financial support from The Coordination for the Improvement of Higher Education Personnel (CAPES), The State of São Paulo Research Foundation (FAPESP) and National Council for Scientific and Technological Development (CNPq), Brazil.

\section{REFERENCES}

1 ANDRIÃO-ESCARSO SH., MANCIN AC., MANCUSO LC., SOARES AM., SAMPAIO SV., TOYAMA MH., MARANGONI S., OLIVEIRA B., GIGLIO JR. Isolation and characterization of a cloting factor from Bothrops jararacussu snake venom. J. Venom. Anim. Toxins, 1997, 3, 155.

2 BARRIE WW., SCHENK WG. Improvement in blood flow through a critical arterial stenosis by defibrination with ancrod. J. Arch. Surg., 1976, 111, 561-3.

3 BELL WR. Defibrinogenating Enzymes. Drugs, 1997, 54, 18-31.

4 CHANG MC., HUANG TF. Characterization of a thrombin-like enzyme, grambin, from the venom of Trimeresurus gramineus and its in vivo antithrombotic effect. Toxicon, 1995, 33, 1087-98.

5 ESCHENFELDER V. Ancrod as an antithrombotic and thrombolytic agent. In: ZAVOICO G. Ed. Advances in anticoagulant and antithrombotic and thrombolytic therapeutics. Southbrough: IBC Biomedical Library Series, 1996.

6 FARSKY SH., GONÇALVES LR., CURY Y. Characterization of local tissue damage evoked by Bothrops jararaca venom in the rat connective tissue microcirculation: an intravital microscopic study. Toxicon, 1999, 37, 1079-83.

7 GENE JA., ROY A., ROJAS G., GUTIÉRREZ JM., CERDAS L. Comparative study on coagulant, defibrinating, fibrinolytic and fibrinogenolytic activities of Costa Rican crotaline snake venoms and their neutralization by a polyvalent antivenom. Toxicon, 1989, 27, 841-8. 
8 GOMIS-RUTH FX., KRESS LF., BODE W. First structure of a snake venom metalloproteinase: a prototype for matrix metalloproteinases/collagenases. EMBO J., 1993, 12, 4151-57.

9 HITE LA., JIA LG., BJARNASON JB., FOX JW. cDNA sequences for four snake venom metalloproteinases: structure, classification, and their relationship to mammalian reproductive proteins. Arch. Biochim. Biophys., 1994, 308, 182-91.

10 ITZHAKI RF., GILL DM. A micro-biuret method for estimating proteins. Anal. Biochem., 1964, 9, 401-10.

11 KINI RM., EVANS HJ. Inhibition of platelet aggregation by a fibrinogenase from Naja nigricollis venom is independent of fibrinogen degradation. Biochem. Biophys. Acta, 1991, 1095, 117-21.

12 KINI RM., EVANS HJ. Structural domains in venom proteins: evidence that metalloproteinases and nonenzymatic platelet aggregation inhibitors (disintegrins) from snake venoms are derived by proteolysis from a common precursor. Toxicon, 1992, 30, 265-93.

13 LAEMMLI UK. Cleavage of structural proteins during the assembly of the head of bacteriophage T4. Nature,1970, 227, 680-5.

14 LATALLO ZS. Retrospective study on complications and adverse effects of treatment with thrombin-like enzymes - a multicentre trial. Thromb. Haemost., 1983, 50, 604-9.

15 LEE WH., ZHANG Y., WANG WY., XIONG YL., GAO R. Isolation and properties of a blood coagulation factor $X$ activator from the venom of king cobra (Ophiophagus hannah). Toxicon, 1995, 33, 1263-76.

16 MAHIR MS., HYND JW., FLUTE PT., DORMANDY JA. Effect of defibrinogenation on the early patency rate of experimental small calibre arterial grafts. Br. J. Surg., 1987, 74, 508-10.

17 MARKLAND FS. Snake venoms and the hemostatic system. Toxicon, 1998, 36, 1749-1800.

18 MARRAKCHI N., BARBOUCHE R., BON C., EL AYEB M. Cerastatin, a new potent inhibitor of platelet aggregation from the venom of the Tunisian viper, Cerastes cerastes. Toxicon, 1997, 35, 125-35.

19 MARRAKCHI N., ZINGALI R., KAROUI H., BON C., EL AYEB M. Cerastocytin, a new thrombin-like platelet activator from the venom of the Tunisian viper Cerastes cerastes. Biochem. Biophys. Acta, 1995, 1244, 147-56. 
20 MATSUI T., FUJIMURA Y., TITANI K. Snake venom proteases affecting hemostasis and thrombosis. Biochem. Biophys. Acta, 2000, 1477, 146-56.

21 MAZZI MV., MARCUSSI S., CARLOS GB., STABELI RG., FRANCO JJ., TICLI FK., CINTRA AC., FRANCA SC., SOARES AM., SAMPAIO SV. A new hemorrhagic metalloprotease from Bothrops jararacussu snake venom: isolation and biochemical characterization. Toxicon, 2004, 44, 215-23.

22 MAZZI MV., MAGRO AJ., AMUI SF., OLIVEIRA CZ., TICLI FK., STABELI RG., FULY AL., ROSA JC., BRAZ AS., FONTES MR., SAMPAIO SV., SOARES AM. Molecular characterization and phylogenetic analysis of BjussuMP-I: a RGD-P-III class hemorrhagic metalloprotease from Bothrops jararacussu snake venom. J. Mol. Graph. Model., 2006, 26, 69-85.

23 MIYATA S., GOTO S., FEDERICI AB., WARE J., RUGGERI ZM. Conformational changes in the $A 1$ domain of von Willebrand factor modulating the interaction with platelet glycoprotein Ibalpha. J. Biol. Chem., 1996, 271, 9046-53.

24 MORAN JB., GEREN CR. Characterization of a fibrinogenase from northern copperhead (Agkistrodon contortrix mokasen) venom. Biochem. Biophys. Acta, 1981, 659, 161-8.

25 OLIVEIRA F., RODRIGUES VM., BORGES MH., SOARES AM., HAMAGUCHI A., GIGLIO JR., HOMSI-BRANDEBURGO MI. Purification and partial characterization of a new proteolytic enzyme from the venom of Bothrops moojeni (COISSACA). Biochem. Mol. Biol. Int., 1999, 47, 1069-77.

26 OUYANG C., HUANG T. Alpha and beta-fibrinogenases from Trimeresurus gramineus snake venom. Biochem. Biophys. Acta, 1979, 571, 270-83.

27 OUYANG C., TENG CM., HUANG TF. Characterization of snake venom components acting on blood coagulation and platelet function. Toxicon, 1992, 30, 945-66.

28 PANDYA BV., BUDZYNSKI AZ. Anticoagulant proteases from western diamondback rattlesnake (Crotalus atrox) venom. Biochemistry, 1984, 23, 460-70. 29 RODRIGUES VM., SOARES AM., ANDRIÃO-ESCARSO SH., FRANCESCHI AM., RUCAVADO A., GUTIÉRREZ JM., GIGLIO JR. Pathological alterations induced by neuwiedase, a metalloproteinase isolated from Bothrops neuwiedi snake venom. Biochimie, 2001, 83, 471-9. 
30 STOCKER K. Snake venom proteins affecting hemostasis and fibrinolysis, In: STOCKER KF. Ed. Medical Use of Snake Venom Proteins. Boca Raton: CRC Press, 1990, 97-160.

31 STOCKER KF., MEIER K. Thrombin-like snake venom enzymes. In: PIRKLE H., MARKLAND FS. Eds. Hemostasis and Animal Venoms. New York: Marcel Dekker, 1988.

32 SWENSON S., TOOMBS CF., PENA L., JOHANSSON J., MARKLAND FS. Alpha-fibrinogenases. Curr. Drug Targets Cardiovasc. Haematol. Disord., 2004, 4, 417-35.

33 TAKEYA H., NISHIDA S., MIYATA T., KAWADA S., SAISAKA Y., MORITA T., IWANAGA S. Coagulation factor $X$ activating enzyme from Russell's viper venom (RVV-X). A novel metalloproteinase with disintegrin (platelet aggregation inhibitor)like and C-type lectin-like domains. J. Biol. Chem., 1992, 267, 14109-17.

34 THOMAZINI-SANTOS IA., MENDES-GIANNINI MJS., TOSCANO E., MACHADO PEA., LIMA CRG., BARRAVIERA B. The evaluation of clotting time in bovine thrombin, reptilase, and thrombin-like fraction of Crotalus durissus terrificus venom using bovine, equine, ovine, bubaline and human cryoprecipitates, J. Venom. Anim. Toxins, 1998, 4, 120-36.

35 THOMAZINI-SANTOS IA., BARRAVIERA SRCS., MENDES-GIANNINI MJS., BARRAVIERA B. Surgical Adhesives. J. Venom. Anim. Toxins, 2001, 7, 159-71.

36 TRAUTSCHOLD I., WERLE E., ZICKGRAF-RÜDEL G. On the kallikrein-trypsininhibitor. Arzneimittelforschung, 1966, 16, 1507-15.

37 VIEIRA DF., WATANABE L., SANT'ANA CD., MARCUSSI S., SAMPAIO SV., SOARES AM., ARNI RK. Purification and characterization of jararassin-I, a thrombinlike enzyme from Bothrops jararaca snake venom. Acta Biochim. Biophys. Sin. Shanghai, 2004, 36, 798-802.

38 ZINGALI RB., CARLINI CR., FRANCISCHETTI IM., GUIMARAES JA. Bothrops jararaca snake venom: effects on platelet aggregation. Toxicon, 1990, 58, 303-16.

39 ZINGALI RB., FERREIRA MS., ASSAFIM M., FRATTANI FS., MONTEIRO RQ. Bothrojaracin, a Bothrops jararaca snake venom-derived (pro)thrombin inhibitor, as an anti-thrombotic molecule. Pathophysiol. Haemost. Thromb., 2005, 34, 160-3. 